\title{
Structural and Dielectric Studies of LLDPE/O-MMT Nanocomposites
}

\author{
Bouchaib Zazoum, Eric David ${ }^{\dagger}$, and Anh Dung Ngô \\ Department of Mechanical Engineering, École de Technologie Supérieure (ÉTS), 1100 Notre-Dame Street West, Montreal \\ QC, H3C 1K3, Canada
}

Received June 2, 2014; Accepted June 9, 2014

\begin{abstract}
Nanocomposites made of linear low density polyethylene (LLDPE) and organo-modified montmorillonite (O-MMT) were processed by melt compounding from a commercially available premixed LLDPE/nanoclay masterbatch, at different nanoclay loadings, by co-rotating twin-screw extruder. The morphological and dielectric properties of LLDPE/O-MMT nanocomposites were investigated to understand the structure-dielectric properties relationship in the nanocomposites. The microstructures of the materials were characterized by wide angle X-ray diffraction (WAXD), scanning electron microscopy (SEM), transmission electron microscopy (TEM) and atomic force microscopy (AFM). Initial findings by FTIR spectroscopy characterization indicated the absence of any chemical interaction between LLDPE and nanoclay during the extrusion process, while DSC showed that a $1 \%$ wt loading of nanoclay particles increased the degree of crystallinity of the nanocomposites samples. On the other hand, XRD, SEM, TEM and AFM indicated that nanoclay layers were intercalated or exfoliated in the LLDPE matrix. A correlation between the structure and dielectric properties of LLDPE/O-MMT nanocomposites was found and discussed.
\end{abstract}

Keywords: Nanocomposites, Microstructure, Dielectric response, Breakdown strength

\section{INTRODUCTION}

Polyethylene is extensively used as groundwall insulation in high and medium voltage electric cables due to its good electrical insulating properties. However, many of its physical properties need to be improved in order to broaden its engineering application. It has been observed that adding a small amount of nanoclay (layered silicates) to some thermoplastics as reinforcing fillers to form nanocomposites material leads not only to an improvement of the mechanical and thermal properties[1-4], but also to an enhancement of the dielectric properties of these materials [5-12].

There are three typical different processing procedures for preparing nanocomposites: (1) in-situ polymerization, (2) solution blending, and (3) melt compounding. The latter is

${ }^{\dagger}$ Author to whom all correspondence should be addressed: E-mail: eric.david@etsmtl.ca

Copyright $(2014$ KIEEME. All rights reserved.

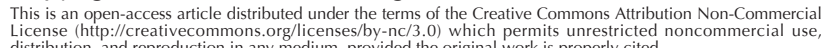
distribution and reproduction in considered to be the most convenient and effective technique for producing nanocomposites, and uses twin-screw extruder. The procedure offers economic benefits and ecological advantages.

The morphology of polymer clay nanocomposites can be classified into three different structures: (1) unmixed nanocomposites, in which polymer chains do not penetrate between silicate layers; (2) intercalated nanocomposites, in which polymer chains are intercalated between silicate layers, and (3) exfoliated nanocomposites, in which the organoclay plates are separated by an average distance that depends on the organoclay plates concentration, and the individual silicate layers are randomly distributed in the polymer matrix. In this case, X-ray diffraction does not show any 001 diffraction peak. The main problem in the fabrication of nanocomposites is the dispersion of the individual clay platelets into the polyethylene matrices due to the incompatibility of hydrophobic polyolefin with hydrophilic nanoclay [13]. To render clay platelets compatible with the polymer matrix, a surface treatment, which uses quaternary alkyl ammonium cations [14], is completed via ion-exchange reactions with cationic surfactants. 
The purpose of this paper is to examine the effect of nanoclay dispersion and to understand the relationship between the structure and dielectric properties of LLDPE/O-MMT nanocomposites.

\section{EXPERIMENT}

\subsection{Materials}

Linear low density polyethylene (LLDPE, FPs117, NOVA Chemicals), with a melt flow index (MFI) of $1 \mathrm{~g} / 10 \mathrm{~min}$ and a density of $0.917 \mathrm{~g} / \mathrm{cm}^{3}$, was used as matrix. A commercial masterbatch of LLDPE/O-MMT (NanoMax) containing $50 \mathrm{wt} \%$ of organo-modified Montmorillonite (O-MMT) was supplied by Nanocor. Maleic anhydride grafted linear low density polyethylene (LLDPE-g-MA, Fusabond M603, DuPont), having a density of $0.940 \mathrm{~g} / \mathrm{cm}^{3}$ and MFI of $25 \mathrm{~g} / 10 \mathrm{~min}$, was used as a compatibilizer.

\subsection{Sample preparation}

The LLDPE, M603 and commercial master-batch of LLDPE/ O-MMT were dried at $40^{\circ} \mathrm{C}$ in a vacuum oven for a minimum of $48 \mathrm{hrs}$ prior to extrusion. Nanocomposites were prepared by an extrusion process using a co-rotating twin screw extruder (Haake Polylab Rheomex OS PTW16, D = $16 \mathrm{~mm}, \mathrm{~L} / \mathrm{D}=40$ ), coupled with a Haake Metering Feeder in order to control the feed rate. The temperature profile from hopper to die used in this study was $140 \sim 180^{\circ} \mathrm{C}$, the feed rate was fixed at $1 \mathrm{~kg} /$ $\mathrm{h}$, and the screw speed was set at $140 \mathrm{rpm}$. All materials were manually pre-mixed, before introduction into the twin-screw extruder.

The pellets obtained after extrusion were press-molded to form thin plates (590 $\mu \mathrm{m}$ thickness) using an electrically heated hydraulic press. The molding temperature and pressure were $178^{\circ} \mathrm{C}$ and $5 \mathrm{MPa}$, respectively. A summary of the compositions of the LLDPE/clay nanocomposites used is provided in Table 1.

\section{CHARACTERIZATION AND MEASUREMENTS}

\subsection{X-ray diffraction (XRD)}

The characterization of nanocomposite structure was performed using an X-ray diffractometer (PANanalytical X'Pert Pro) with $\mathrm{K} \alpha$ radiation $(\lambda=1.5418 \AA)$, at an accelerating voltage of $40 \mathrm{kV}$ and an electrical current of $45 \mathrm{~mA}$. The scanning was conducted from $2^{\circ}$ to $9^{\circ}$ with a step size of $0.0334^{\circ}$ and the counting time was $200 \mathrm{~ms}$ per step. The intercalate spacing between the planes in the atomic lattice $d_{001}$ was calculated by using Bragg's law [15]:

$$
2 d \sin \theta=\lambda
$$

\subsection{Transmission electron microscopy (TEM)}

The degree of dispersion of the nanoclays in the polymer matrix was examined by Transmission Electron Microscopy (TEM). Ultra-thin sections of $50-80 \mathrm{~nm}$ in thickness were cut from the molded plaque of LLDPE/O-MMT nanocomposites at $-120^{\circ} \mathrm{C}$, using an ultramicrotome equipped with a diamond knife. These samples were then examined by high-resolution JEOL JEM$2100 \mathrm{~F}$ TEM with an accelerating voltage of $200 \mathrm{kV}$.
Table 1. Sample formulation and designation.

\begin{tabular}{cccc}
\hline Sample designation & LLDPE (wt\%) & O-MMT (wt\%) & LLDPE-g-MA (wt\%) \\
\hline \hline MB & 50 & 50 & 0 \\
\hline LLDPE & 100 & 0 & 0 \\
\hline LLDPE+1\%O-MMT & 99 & 1 & 0 \\
\hline LLDPE+3\% O-MMT & 97 & 3 & 0 \\
\hline $\begin{array}{c}\text { LLDPE+3\%O- } \\
\text { MMT+10\%M603 }\end{array}$ & 87 & 3 & 10 \\
\hline LLDPE+5\% O-MMT & 95 & 5 & 0 \\
\hline
\end{tabular}

\subsection{Atomic force microscopy (AFM)}

Morphological investigations of the LLDPE/clay nanocomposites were carried out by Atomic Force Microscopy (DiNanoScope, Vecco, USA) in tapping mode. Images of the surface topography were then analyzed using the Nanoscope (R) III software, Version 5.30r.sr3. Samples with a thickness of $560 \mu \mathrm{m}$ were used, and all measurements were carried out at ambient conditions.

\subsection{Scanning electron microscope (SEM)}

The sample micro-structure was examined by Hitachi Scanning Electron Microscopy (SEM). Samples were first embrittled in liquid nitrogen and then snapped off by hand and coated with a $2 \mathrm{~nm}$ platinum layer in order to avoid electrostatic charging during the microscopic observations.

\subsection{Differential scanning calorimetry (DSC)}

The thermal behavior of pure LLDPE and LLDPE/O-MMT nanocomposites was observed using a Perkin-Elmer Differential Scanning Calorimeter Pyris 1 instrument. The temperature calibration of the DSC was performed using indium. During each run, the LLDPE and its nanocomposites were heated from $30^{\circ} \mathrm{C}$ to $180^{\circ} \mathrm{C}$, at a heating rate of $10^{\circ} \mathrm{C} / \mathrm{min}$, in nitrogen atmosphere.

\subsection{Fourier transform infrared spectroscopy (FTIR)}

Fourier transform infrared (FTIR) spectra were obtained using a Thermo Electron Nicolet 6700 FT-IR spectrometer instrument. Thin film samples were cut from the compression-molded sheet films. The measurements were carried out at a spectral resolution of $4 \mathrm{~cm}^{-1}$ in the $400 \sim 4,000 \mathrm{~cm}^{-1}$ wavenumber range, with accumulations of 32 scans at room temperature. Spectra were collected in transmittance mode.

\subsection{Dielectric relaxation spectroscopy}

Dielectric relaxation spectroscopy experiments were carried out using a Novocontrol alpha-N Analyzer in the $10^{-2}$ to $10^{5} \mathrm{~Hz}$ frequency domain at temperatures of $40^{\circ} \mathrm{C}$. The temperature was controlled using a Novotherm system, with a stability of $0.5^{\circ} \mathrm{C}$.

The samples were sandwiched between two gold-plated electrodes measuring $40 \mathrm{~mm}$ in diameter to form a parallel-plate geometry capacitor.

The obtained complex dielectric permittivity is given by:

$$
\varepsilon^{*}(\omega)=\varepsilon^{\prime}(\omega)-i \varepsilon^{\prime \prime}(\omega)
$$

where $\varepsilon^{\prime}(\omega)$ represents the real part, $\varepsilon^{\prime \prime}(\omega)$ represents the imaginary part, and $\omega=2 \pi \mathrm{f}$ is the angular frequency. 


\subsection{Dielectric breakdown strength}

The dielectric breakdown field was measured according to the ASTM D 149 standard. The specimens were placed between two $12.5 \mathrm{~mm}$ hemispherical electrodes and held by a small applied pressure. The whole setup was immerged in mineral oil (Voltesso 35, ESSO Imperial Oil). The rate-of-rise was set to $2 \mathrm{kV} / \mathrm{s}$ and a 60 $\mathrm{Hz}$ voltage was raised until the sample failed.

The two-parameter Weibull statistical distribution [16] was used to treat the dielectric strength data. The Weibull statistical distribution in the case of two-parameters can be written as follows:

$$
P(E)=1-\exp \left[-(E / \alpha)^{\beta}\right]
$$

where $\mathrm{P}(\mathrm{E})$ denotes the cumulative distributive function of dielectric strength, $\mathrm{E}$ is the experimental dielectric strength, $\alpha$ is the scale parameter which represents the breakdown strength at $P(\alpha)=0.632$, and finally, $\beta$ is a shape parameter related to the data scattering. According to the IEEE 930-2004 standard, the experimental probability of failure $\mathrm{P}(\mathrm{i}, \mathrm{n})$ associated with the $\mathrm{E}_{\mathrm{i}}$ data can be approximated by:

$$
P(i, n)=\frac{i-0.44}{i+0.25}
$$

where $i$ is the $i^{\text {th }}$ result when the breakdown values are sorted in ascending order and $\mathrm{n}$ is the number of data points. In this paper, $\mathrm{n}=20$.

The commonly used $90 \%$ confidence intervals have been used to compare sets of data by verifying the overlapping of the confidence limits at the $63.2^{\text {th }}$ percentile.

\section{RESULTS AND DISCUSSION}

\subsection{X-ray diffraction (XRD) technique}

Figure 1 shows the X-ray diffraction spectra of the O-MMT masterbatch (MB), LLDPE+3\% O-MMT and LLDPE+3\% O-MMT $+10 \%$ M603 nanocomposites. The $\mathrm{d}_{001}$ diffraction peak for the $\mathrm{O}$-MMT masterbatch is about $2 \theta=3.13^{\circ}$, corresponding to a basal spacing $\mathrm{d}_{001}$ of $2.82 \mathrm{~nm}$. When the O-MMT masterbatch was diluted with pure LLDPE, the diffraction peak was found to shift to a smaller angle, indicating the increase in $\mathrm{d}_{001}$ spacing of the galleries of the organoclay. For the ternary nanocomposites LLDPE+3\% O-MMT+10\% M603, the reduction in the diffraction intensity and the disappearance of the basal peak suggested that $\mathrm{O}-\mathrm{MMT}$ is exfoliated in the polymer matrix.

\subsection{Microstructure of nanocomposites}

Transmission electron microscopy was employed in order to directly visualize the nanocomposites' structure and to confirm XRD information about the quality of dispersion for silicate platelets in the polymer matrix. TEM micrographs of LLDPE+3\% O-MMT and LLDPE+3\% O-MMT+10\% M603 are shown in Fig. 2. It can be seen that clay is presented as tactoids in the LLDPE+3\% O-MMT nanocomposites (Fig. 2(a)). Obviously, when the compatibilizer is added, the microstructure of the nanocomposites is significantly improved, and this is presented as a combination of intercalated and exfoliated nanoclay layers (Fig. 2(b)).

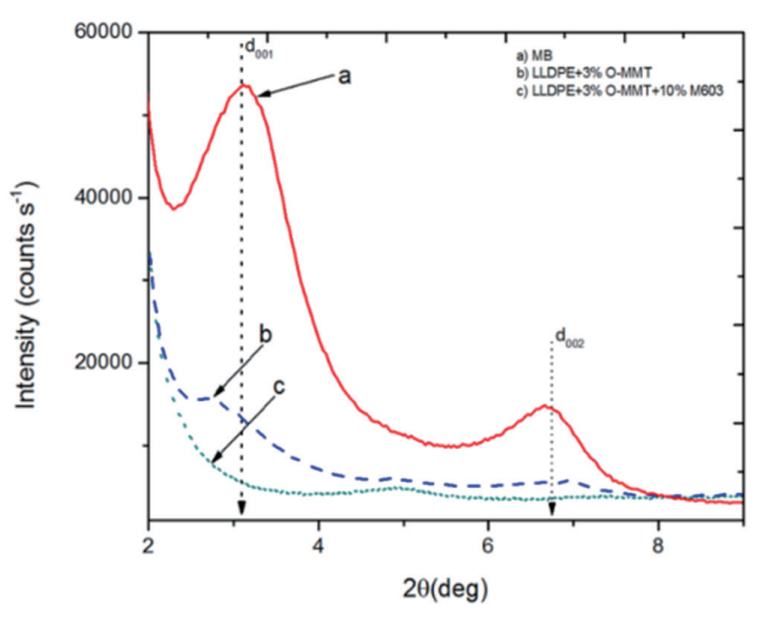

Fig. 1. X-ray diffraction spectrum of LLDPE/clay nanocomposites.

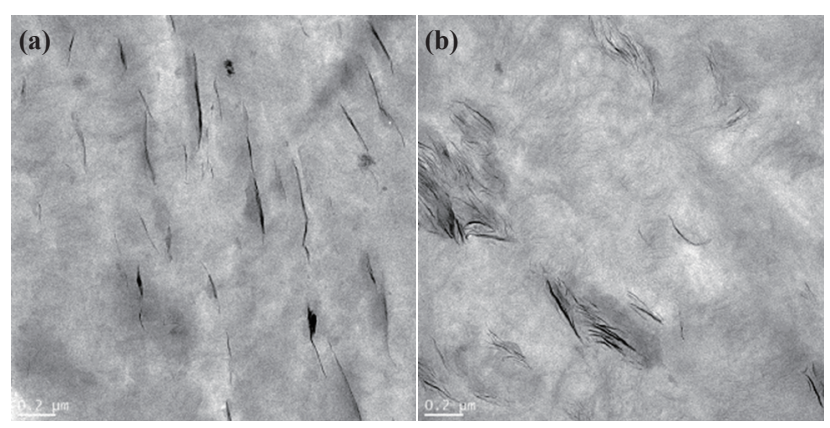

Fig. 2. TEM Micrographs of (a) LLDPE+3\%O-MMT and (b) LLDPE+3\% O-MMT+10\% M603.

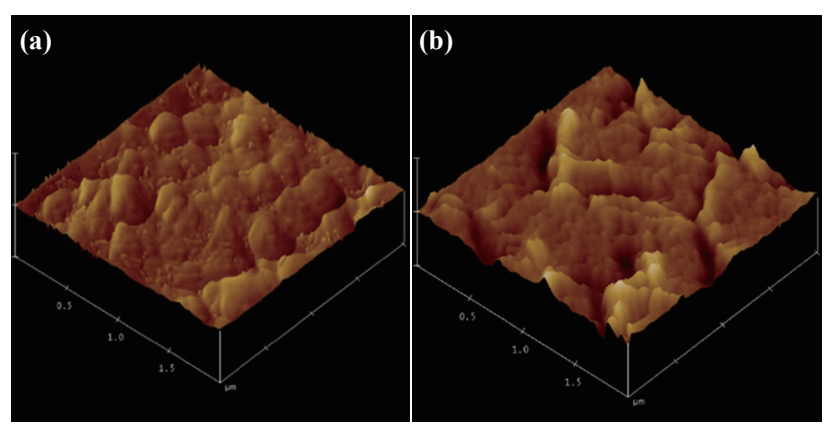

Fig. 3. AFM images of (a) LLDPE+3\% O-MMT and (b) LLDPE+3\% OMMT $+10 \%$ M603 nanocomposites.

\subsection{Atomic force microscopy}

AFM height images of LLDPE+3\% O-MMT and LLDPE+3\% OMMT $+10 \%$ M603 were used in order to study the dispersion of nanoclay in the polymer matrix. The surface properties of these two nanocomposites in 3D height image are shown in Figs. 3(a) and $3(\mathrm{~b})$. From the images, the nanoclay appears brighter than the polyethylene matrix. It is obvious that in the compatibilized nanocomposites, the agglomerates are broken into small tactoids and the nanoclays are more homogeneously distributed in the polymer matrix. This leads to a reasonably good dispersion of nanoclay in LLDPE+3\% O-MMT+10\% M603 nanocomposites [17]. These obtained results are also well corroborated by XRD and TEM measurements. 


\subsection{Thermal properties}

Differential Scanning Calorimetry (DSC) was used to measure the melting temperature and the fusion enthalpy $\Delta \mathrm{H}_{\mathrm{F}}$. The degree of crystallinity was calculated as

$$
\% \chi=\frac{\Delta H_{F}}{\Delta H_{F}^{0}(1-\varphi)}
$$

where $\Delta \mathrm{H}_{\mathrm{F}}$ is the heat of fusion $(\mathrm{J} / \mathrm{g}), \Delta H_{F}^{0}$ is the theoretical heat of fusion of $100 \%$ crystalline LLDPE $(293 \mathrm{~J} / \mathrm{g}$ ) and $\varphi$ is the weight fraction of O-MMT.

DSC numerical data of LLDPE and its nanocomposites are reported in Table 2. It can be seen that the addition of nanoclay to the LLDPE matrix had no significant impact on the melting temperature for all the samples. However, the crystallinity of LLDPE/O-MMT samples was found to increase at concentrations of nanoclay of $1 \mathrm{wt} \%$. This observation could be explained by the fact that nanoclay layers acted as nucleating agents and facilitated the crystal growth. On the other hand, the degree of crystallinity was found to slightly decrease with further increases of nanoclay concentration ( $5 \mathrm{wt} \%$ ). A possible explanation for this could be that intercalated nanoclay layers of O-MMT limit the growth of the polymer spherulites.

\subsection{FTIR spectroscopy}

Transmittance Fourier Transform Infrared Spectroscopy was used to quantify the possible thermal degradation and monitor the motion of molecular chain of pure LLDPE and LLDPE/OMMT nanocomposites.

Figure 4 shows the infrared spectra of LLDPE (0 run), LLDPE (1 run) and LLDPE/O-MMT (1 run) nanocomposites with different O-MMT contents. Comparing the infrared spectra of LLDPE (0 run) with that of LLDPE (1 run) indicates the absence of any oxidation phenomena during the one-run extrusion process. The binary nanocomposites LLDPE/O-MMT show only the characteristic peaks for both pure LLDPE and O-MMT. The absence of any new peaks indicates the absence of any oxidation or chemical reactions between the nanoclay and polymer matrix.

$\mathrm{O}$-MMT has characteristic peaks at $464 \mathrm{~cm}^{-1}, 521 \mathrm{~cm}^{-1}$ and $1,047 \mathrm{~cm}^{-1}$; these bands are related to Si-O bending, Al-O stretching and Si-O stretching, respectively [18]. It can be seen that the intensity of the Si-O stretching band increased as the nanoclay content increased. Vaia et al. [19] showed that around $1,469 \mathrm{~cm}$ ${ }^{1}$, the $\mathrm{CH}_{2}$ rocking band is related to the polymer chain motion, and the shift of this peak to the higher wave number indicates a decrease in the polymer chain mobility. The fact that the characteristic peak of the $\mathrm{CH}_{2}$ rocking band in LLDPE/O-MMT nanocomposites with $5 \% \mathrm{wt}$ of nanoclay content was shifted to higher wavenumber $\left(1,471 \mathrm{~cm}^{-1}\right)$ compared to that in pure LLDPE $(1,469$ $\mathrm{cm}^{-1}$ ) can be explained by the fact that the additional $5 \mathrm{wt} \%$ of nanoclay slows down the chain motion, and therefore decreases the crystallinity. This is in agreement with DSC results.

\subsection{Effect of screw speed on morphological characterization}

To study the effect of screw speed on clay dispersion of nanoclay layers in the polymer matrix, two different speeds $(50 \mathrm{rpm}$ and $350 \mathrm{rpm}$ ) were selected. The nanoclay content was $3 \mathrm{wt} \%$ and the compatibilizer M603 concentration was set at 10\% wt. Figure 5 shows the morphology of the ternary nanocomposite LLDPE+3\% O-MMT+10\% M603 on a nanometric scale, using scanning electron microscopy (SEM). A comparison between the
Table 2. DSC results for pure LLDPE and LLDPE/O-MMT nanocomposites.

\begin{tabular}{ccc}
\hline Sample & Melting Point $\left({ }^{\circ} \mathrm{C}\right)$ & Crystallinity (\%) \\
\hline \hline LLDPE & 107.7 & 33.7 \\
\hline LLDPE+1\%O-MMT & 108.0 & 36.8 \\
\hline LLDPE+3\% O-MMT & 107.1 & 35.3 \\
\hline LLDPE+3\%O-MMT+10\%M603 & 107.1 & 35.2 \\
\hline LLDPE+5\% O-MMT & 107.7 & 34.0 \\
\hline
\end{tabular}

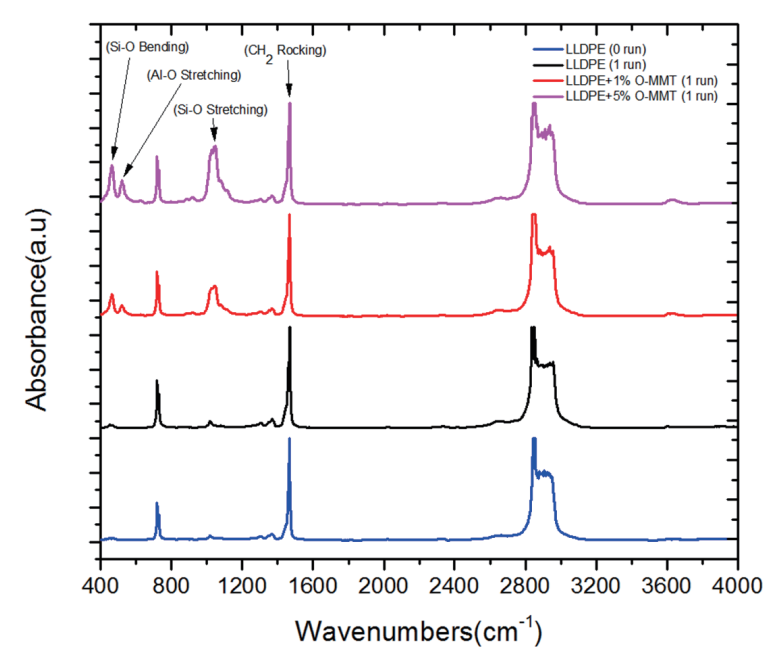

Fig. 4. FTIR spectra of LLDPE and its nanocomposites.

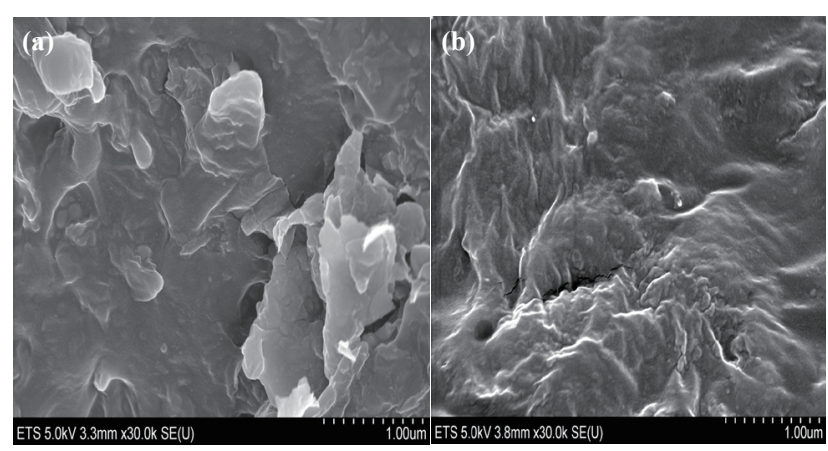

Fig. 5. SEM micrograph of LLDPE+3\% O-MMT+10\% M603 for a screw speed of (a) $50 \mathrm{rpm}$ and (b) $350 \mathrm{rpm}$.

morphology of the nanocomposite extruded at low speed (Fig. 5(a)) and that at high speed (Fig. 5(b)) shows that the density and size of aggregates decreased as the screw speed increased. The screw speed led to an improvement in the nanoclay dispersion and to more exfoliated layers.

\subsection{Broadband dielectric spectroscopy}

Figure 6 shows the dielectric response of LLDPE, LLDPE $+1 \% \mathrm{O}-\mathrm{MMT}$, LLDPE+3\% O-MMT, LLDPE+3\% OMMT+10\% M603 and LLDPE+5\% O-MMT nanocomposites obtained using Frequency-Domain dielectric spectroscopy at $40^{\circ} \mathrm{C}$ in the $10^{-2}$ to $10^{5} \mathrm{~Hz}$ frequency range. Figure 6(a) shows that the relative permittivity $\varepsilon^{\prime}$ of the 1,3 and $5 \mathrm{wt} \%$ LLDPE/O-MMT nanocomposites sharply decreases. The corresponding dielectric loss $\varepsilon$ " shows a relaxation peak at around $10^{2} \mathrm{~Hz}$, as shown in Fig. 6(b). It is also observed that both real and imaginary permittivity increase with decreasing frequency. It is evident that the 

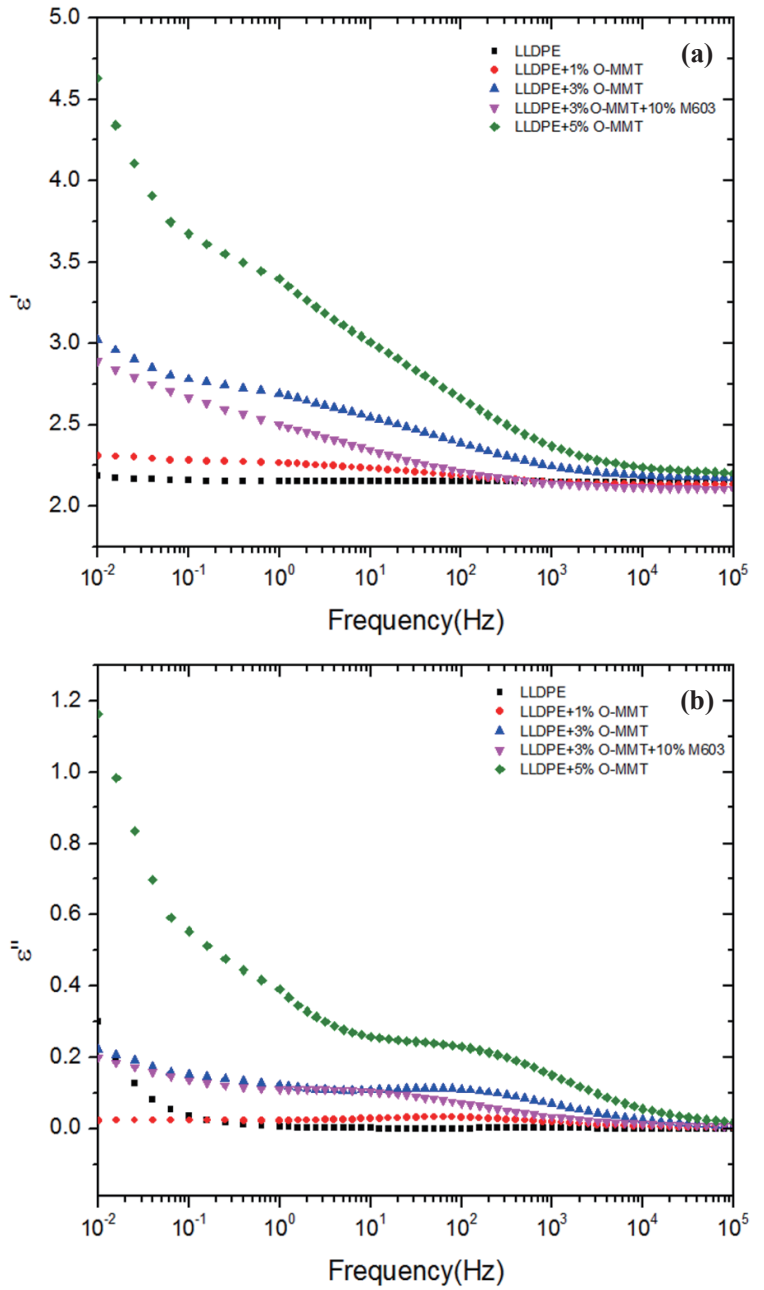

Fig. 6. Relative permittivity (a) and dielectric losses (b) as a function of frequency of LLDPE and its nanocomposites at $40^{\circ} \mathrm{C}$.

$\varepsilon "$ peak observed in the nanocomposites is due to the addition of nanoclay, because there are no dielectric relaxation peaks for pure LLDPE in this frequency range. The peak of the relaxation processes presented in the nanocomposites is attributable to a Maxwell-Wagner-Sillars polarization associated with the blocking of charges at the interfaces between two inhomogeneous phases of different permittivities and conductivities, namely the polymer matrix and the silicates filler [20-22]. Furthermore, when $10 \%$ wt of compatibilizer was used to improve the dispersion of the clay platelets, this relaxation peak was found to shift towards low frequencies.

\subsection{Dielectric breakdown measurements}

Figure 7 shows the Weibull cumulative failure probability plot for the dielectric strength of pure LLDPE and its nanocomposites (without confidence bounds, for clarity). As reported in Table 3, for LLDPE, LLDPE+1\% O-MMT, LLDPE+3\% O-MMT, LLDPE+3\% O-MMT+10\% M603 and LLDPE+5\% O-MMT, the scale parameters $\alpha$ were 58.8, 62.9, 66.6, 69.6 and $69.9 \mathrm{kV} / \mathrm{mm}$, respectively, and the shape parameters $\beta$ were $17.1,17.9,18.2$, 17.9 and 12.3 , respectively. It can clearly be seen from the scale parameter values $\alpha$ and from the confidence intervals that increasing the O-MMT concentration in a binary nanocomposite leads to a noticeable increase in the material dielectric strength. This could be explained by the major role played by the interface

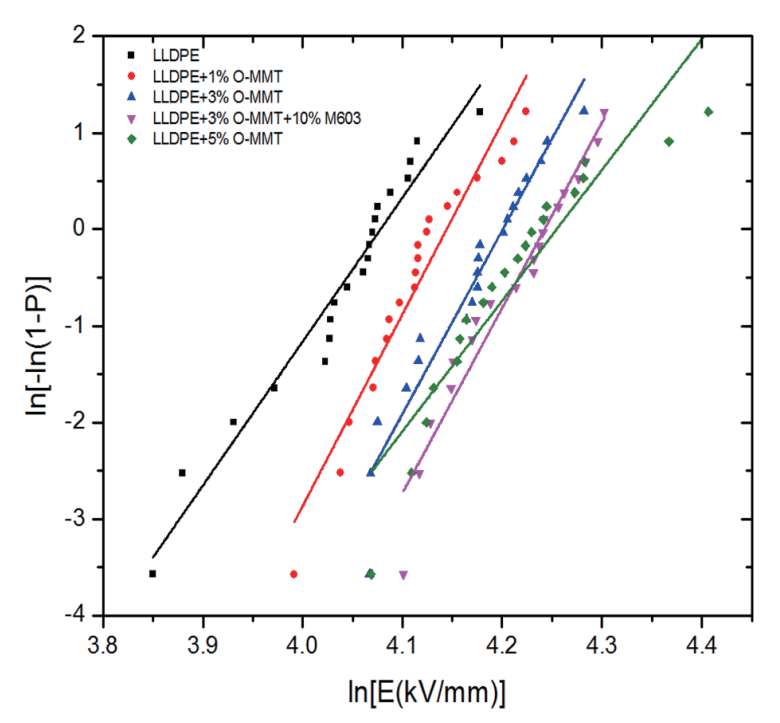

Fig. 7. Weibull probability plot of dielectric strength of LLDPE and its nanocomposites.

Table 3. Weibull parameters for dielectric breakdown strength of LLDPE and its nanocomposites.

\begin{tabular}{ccccc}
\hline Samples & $\begin{array}{c}\text { Average } \\
\text { thickness } \\
(\mathrm{mm})\end{array}$ & $\begin{array}{c}\alpha \\
(\mathrm{kV} / \mathrm{mm})\end{array}$ & $\beta \quad \begin{array}{c}\text { Confidence } \\
\text { intervals for } \alpha \\
(\mathrm{kV} / \mathrm{mm})\end{array}$ \\
\hline LLDPE & 0.61 & 58.8 & 17.1 & $57.4 \sim 60.1$ \\
\hline LLDPE+1\% O-MMT & 0.58 & 62.9 & 17.9 & $61.4 \sim 64.2$ \\
\hline LLDPE+3\% O-MMT & 0.57 & 66.6 & 18.2 & $65.1 \sim 68.0$ \\
\hline LLDPE+3\%O-MMT+10\% M603 & 0.56 & 69.6 & 17.9 & $68.0 \sim 71.1$ \\
\hline LLDPE+5\% O-MMT & 0.58 & 69.9 & 12.3 & $67.6 \sim 72.0$ \\
\hline
\end{tabular}

between the LLDPE matrix and the nanoclay particles which could impact the space charge distribution and charge densities. In turn, this probably led to a better distribution of the electrical stress [23]. When the compatibilizer was added to LLDPE+3\% OMMT nanocomposites, further improvements of the breakdown strength were noticed. A possible explanation for this is related to the change of microstructure that occurred with the addition of compatibilizer into LLDPE+3\% O-MMT nanocomposites. This change of microstructure was already underlined by the microscopic observation results discussed above.

\section{CONCLUSIONS}

A commercial nanoclay masterbatch was used in this study to prepare LLDPE/O-MMT nanocomposites. Microstructural characterizations revealed that the degree of dispersion was improved by the incorporation of a compatibilizer. No relaxation peaks were observed in the pure LLDPE, but one was found in the nanocomposites and was attributed to an interfacial process. When a compatibilizer was added, this peak was found to shift towards low frequencies.

Dielectric strength measurements showed that in LLDPE/OMMT nanocomposites, significant improvements in dielectric breakdown strength can be achieved, in comparison with pure LLDPE. It was also shown that the improvement of the quality of dispersion leads to a further improvement in dielectric breakdown strength. This may suggest a correlation between nanocomposite structure and dielectric breakdown strength. 


\section{ACKNOWLEDGMENTS}

The authors are grateful for financial support from the National Sciences and Engineering Research Council of Canada (NSERC). We also thank Professor Abdellah Ajji, Ahmad Zohre Vand and Weawkamol Leelapornpisit from the Department of Chemical Engineering, École Polythechnique de Montréal, for the TEM measurements.

\section{REFERENCES}

[1] Y. Han, Z. Wang, X. Li, J. Fu, and Z. Cheng, Current Trends in Polymer Science, 6, 1 (2001).

[2] S. Hotta and D. Paul, Polymer, 45, 7639 (2004). [DOI : http:// dx.doi.org/10.1016/j.polymer.2004.08.059].

[3] M. Kawasumi, N. Hasegawa, M. Kato, A. Usuki, and A. Okada, Macromolecules, 30, 6333 (1997). [DOI : http://dx.doi. org/10.1021/ma961786h].

[4] L. Utracki and M. Kamal, Arabian Journal Science \& Engineering--Special Issue, 27, 43 (2002).

[5] H. Tan and W. Yang, Mechanics of Materials, 30, 111 (1998). [DOI : http://dx.doi.org/10.1016/S0167-6636(98)00027-1].

[6] X. Kornmann, H. Lindberg, and L. A. Berglund, Polymer, 42, 1303 (2001). [DOI : http://dx.doi.org/10.1016/S00323861(00)00346-3].

[7] K. Zhao and K. He, Physical Review B, 74, 205319 (2006). [DOI : http://dx.doi.org/10.1103/PhysRevB.74.205319].

[8] H. Awaji, Y. Nishimura, S. M. Choi, Y. Takahashi, T. Goto, and S. Hashimoto, Journal of the Ceramic Society of Japan, 117, 623 (2009). [DOI : http://dx.doi.org/10.2109/jcersj2.117.623].

[9] L. Chen and G. Chen, Polymer Composites, 30, 101 (2009). [DOI : http://dx.doi.org/10.1002/pc.20539].
[10] P. Kim, N. M. Doss, J. P. Tillotson, P. J. Hotchkiss, M. J. Pan, S. R. Marder, Jiangyu Li, Jeffery P. Calame, and Joseph W. Perry, ACS Nano, 3, 2581 (2009). [DOI : http://dx.doi.org/10.1021/ nn9006412].

[11] C. D. Green, A. S. Vaughan, G. R. Mitchell, and T. Liu, Dielectrics and Electrical Insulation, IEEE Transactions on, 15, 134 (2008). [DOI : http://dx.doi.org/10.1109/T-DEI.2008.4446744].

[12] M. Hoyos, N. García, R. Navarro, A. Dardano, A. Ratto, F. Guastavino, and Tiemblo, Journal of Polymer Science Part B: Polymer Physics, 46, 1301 (2008). [DOI : http://dx.doi.org/10.1002/ polb.21464].

[13] M. A. Osman, J. E. P. Rupp, and U. W. Suter, Polymer, 46, 1653 (2005). [DOI : http://dx.doi.org/10.1016/j.polymer.2004.11.112].

[14] X. Zhang, Z. Liu, Q. Li, Y. Leung, K. Ip, and S. Hark, Advanced Materials, 17, 1405 (2005). [DOI : http://dx.doi.org/10.1002/ adma.200401891].

[15] W. Bragg, Proc. of the Royal Society of London. Series A, 89, 246 (1913). [DOI : http://dx.doi.org/10.1098/rspa.1913.0082].

[16] I. Std-930, 2004.

[17] S. I. Hong and J. W. Rhim, LWT - Food Science and Technology, 48, 43 (2012).

[18] J. Madejová, Vibrational Spectroscopy, 31, 1 (2003). [DOI : http://dx.doi.org/10.1016/S0924-2031(02)00065-6].

[19] R. A. Vaia, R. K. Teukolsky, and E. P. Giannelis, Chemistry of Materials, 6, 1017 (1994). [DOI : http://dx.doi.org/10.1021/ cm00043a025].

[20] E. Laredo, M. Grimau, F. Sanchez, and A. Bello, Macromolecules, 36, 9840 (2003). [DOI : http://dx.doi.org/10.1021/ma034954w].

[21] H. Le Huy and J. Rault, Polymer, 35, 136 (1994). [DOI : http:// dx.doi.org/10.1016/0032-3861(94)90061-2].

[22] D. W. McCall and E. W. Anderson, The Journal of Chemical Physics, 32, 237 (1960). [DOI : http://dx.doi.org/10.1063/1.1700907].

[23] J. K. Nelson and J. C. Fothergill, Nanotechnology, 15, 586 (2004). [DOI : http://dx.doi.org/10.1088/0957-4484/15/5/032]. 